\title{
Leadership Characteristics Prioritized by Students in Developing Countries: Pakistani Perspective
}

\author{
Dr Mona Aeysha Khalid \\ Assistant Prof. of Education \\ Panasastra University of Cambodia, Kingdom of Cambodia
}

Gul Muhammad Khan

Ph. D. Scholar

University of Management and Technology, Lahore

Tariq Mahmood

PhD Research Fellow

University of Education, Division of Education, Lahore, Pakistan

Corresponding author: +923014981592, tariq_903@hotmail.com

Doi:10.5901/jesr.2013.v4n3p245

\begin{abstract}
Main salient features for leaders in developing Asian countries may include vigilant, intelligent, hardworking, goal oriented, persistent, determined, and highly motivated to establish a strong sense of teamwork with great vision, while having good and healthy relationships with their employees, being conscious of high moral values and ethical standards. This research paper will identify the strongly emphasized traits of leaders demanded by the young generation of Pakistani students. The study concluded following main findings: The most important trait that they want to see in their leaders is being intelligent having mean value as 1.3 surpassed other mean scores while the second choice was being honest and trustworthy. Students think that leaders must take care of their subordinates and as a human being must attend to their well being. They usually want their leaders to treat them with respect and dignity. On the other side, unstable person is the worst thing for a leader, being dishonest and deceitful minded are rated as second highest traits of bad leaders. Here it is important to note that not to give right instructions is a bad trait but may be excused as compared to other deadly evils.
\end{abstract}

Keywords: leadership, perception, traits of leaders, students.

\section{Introduction}

Leadership is always thought as the best solution for most of the universal problems whether it is school related or business related structure. But the term leadership in general and school leadership in particular is not uniformly defined and understood around the world. Robert Palestini.2009. In addition, there is limited research that can explain how the high quality of leaders in emerging schools (especially the turnaround schools) differ from others., the complexity of the term and the vast level practices lead us towards a new in-depth study about its nature ( Jacky Lumby \& Gary ,2008; Kenneth et al., 2010). As we require a highly effective leadership in our schools and especially to our newly emerging turnaround schools (Kenneth et. al, 2010).

Since educationists (school leaders) roles have dramatically changed in the world, school leaders are now facing lots of new and alarming challenges and obstacles. School leaders mean the persons who want to keep a good relationship with teachers, parents, students and the staff. They work as teachers, administrators, and organizers, perform their duties politically and diplomatically, also act as mediators between internal and external educational matters. Stephan Gerhard Huber. 2004. Many education ministers participating in organizations such as Organization for Economic Cooperation and Development (OECD) have been recognized the importance of school leadership too. So it is very important to understand the phenomenon and utilize the most relevant part of it according to our own culture and specific needs (Jacky, Lumby \& Crow, 2008). 
Leader is defined in the dictionary as one who leads or conducts; one who occupies a prominent place; one who is genius with the force of ideas and character; one who has will power and administrative ability; and the one who direct men in conduct and achievement (Miller, 1920).

With respect to the character and personality, a leader must hold 16 points of leadership: simplicity, earnestness, self control, assiduity, common sense, judgment, justice, enthusiasm, perseverance, tact, courage, faith, loyalty, truthfulness, honor, and acumen. According to writer, these points relative importance would provide another interesting scenario for the students and researcher to deal with (Arthur, 1920).

Irving (2011) has given us five leadership choices to choose from:

- Be suspicious and wary

- Smart is always 360

- Obsess about root cause

- Solutions are problems

- Execute flawlessly

In the 1900s, leaders were usually great when they dictated, had a 'can do' like attitude and they used their authority in some cases. By the 1950s, attention shifted towards leader traits (how these traits help them to function). In the early 1980s, focus was on the visionary leaders (visionary leaders motivate). These leaders were full of insights and shared authority to motivate others to accomplish tasks. In 2000s, today's world, we need more 'strategic' leaders (learners) who remain flexible, creative, adaptive, forward-looking and show its strategic intent. According to the author, strategic leaders are more like being information seeker than information distributor that help to develop new competencies (Larry, 2008).

There are many concepts about leadership in the world in which some are vague, some are general, some are worldly and some are unique. The most popular concepts are : a leader goes ahead and acts as a guiding force; motivates others towards set goals; caches others attention through persuasion and example; give direction to others; coordinates and advises; leads by examples; and uses the authority to lead others (Damazio, 1988). Irving (2011) argued that leaders have to be both decisive and persuasive. There are some traits that every leader must have: The changer (transformational); The re-arranger (transactional); The integrator (convergent); The innovator (entrepreneur); and The anticipator (futuristic). These traits can be overlapped and organized in different weights but from historical point of view, all of these are the basic choices of popular leaders (Irving, 2011)

Almost all successful leaders accomplish the following four practices to leadership success (Kenneth et al., 2010):

- create a sense of direction

- develop the capacities of members towards a path of success.

- redesign the organization

- manage the technical part of the organization. In schools this will be teaching and learning processes.

Palestini (2009) has proposed certain theories of leadership. The trait theory of leadership suggests that leadership can be evaluated by a persons certain personality, social and physical traits. In 1940s and 1950s, trait theory attempted to predict which individuals become effective leaders and which cannot. However, the limited application of trait theory paved the way for other theories like behavioural theory of leadership. During 1950s, researchers started to view a person's behaviour rather than personal traits to learn about effective leadership. Leadership behaviours can be further divided into two categories: production oriented (initiating structure) and employee oriented (concern for people). The formal one is suitable to people who holds an autocratic style. The second one focuses on supporting the individual workers and involves them in decision making. For example a principal who cares for his or her teacher's satisfaction has an employee oriented leadership style.

Moreover, in managerial role theory, Mintzberg suggested ten roles of leadership. Three of them focus on interpersonal ability: figure head, leader and liaison. Three involves information processing: monitor, disseminator, and spokesman. Four are related to decision making: entrepreneur, disturbance handler, and resource allocator, negotiator. This theory is more compatible with situation approach rather than trait or behavioural perspective (Palestini, 2009).

Early situational theory suggests that appropriate behaviour depends on the situation, and effective leaders diagnose the situation, identify the leadership style, and then decide whether they can go ahead with the one decided earlier. It also predicts that traits like being subordinate, supervisor, and task consideration affect the situation oriented leadership style (Palestini, 2009). Frederick Fiedler developed a contingency or situational model of leadership in 1987 and argued that changing an individual's leadership style is difficult, so organizations should put individuals in situations 
that fit with their original style of leadership. Usually managers can choose from being task oriented and relationship oriented styles. Robert Palestini.2009.

Selwyn (2012) has provided a list of key points between command-and-control and system thinking styles of leadership and argued that we need both styles at different times to become successful leaders. Some of them are as follows:

- Top down view vs outcome view

- Specialist roles and standardise vs the whole system and personalise

- Planning and milestones vs vision, beliefs, environment and culture

- Target setting vs autonomous and learning environment

- Wary of risk vs managing risk

- Contractual vs partnership

- Extrinsic motivation vs intrinsic motivation

- Mistrust of staff vs belief in staff

- Transactional relationship vs personal relationships

- Left brain vs right brain

According to David (2012), leadership styles can also be examined with respect to personality types. Among them, one is named as gold personality type in which leader always gives priority to the work. Another personality type named Blue, is composed of leaders who value community, their employees opinions and the involved team work.

The style called green leadership brings intelligence, smart work and analysis of facts and figures together. Orange leaders are action oriented and set examples for others to follow. David (2012) has further elaborated the concept of leadership with respect to leader's personal attributes and relationship traits. To him, effective leadership involves some personal traits like behaving, thinking, strategically supporting corporate goals, communicating effectively, gathering required information, making decisions, developing team work, being assertive, behaving professionally, and managing and reflecting according to the time to time feed back. And the relationship traits for good leadership are:

- Availability

- Facilitating

- Approachability

- Confidentiality

- Self motivation

- Support

- Communication

Since long, researchers have been thinking about the best leadership style. However, in today's world, no one style of leadership is best rather a mixture of styles that would best suit someone according to their own unique circumstances, will be the best style (Robert, 2009).

As per Sharon (2009), good leadership involves effective problem solving skills in which hard work is not always required rather working smart is important and needed in some places more than hard work. For him problem solving and good decision- making are equally important traits for a good leadership. Jeffrey and Jay ( 2011) extended the concept of good leadership by the argument that for a good leader, integrity is the best quality. He should be aware of the needs and emotions of the followers and handle such information wisely to become a good leader. A good leadership requires a vision that motivates others towards future goals. It requires the ability to plan to reach the set goals, decision making and judgmental abilities. Leaders are on the front line, face criticisms and unforeseen set backs that will require courage and passion.

Sharon (2009) has listed 7 attributes : integrity, empathy, emotional intelligence, vision, judgment, courage, and passion. These 7 traits are backbone of leadership. Even one trait missing from some ones personality will not give him a title of leader. The rest of the traits will come behind these ones (Jeffrey and Jay, 2009).

There are seven principles of effective leaders proposed by Palestini (2009).

- be able to adapt their leadership style to the situation

- be keenly aware of the organizational structure and culture.

- be able to engender a sense of trust and respect in their followers.

- agents for change

- well organized, creative and with clear vision

- communicate effectively

- motivate followers and manage the conflicts. 
Leaders consider themselves unique and defining to determine who they are, what and who they will become and then how they will achieve distinct features of success. In this regard, there are many factors that set them apart but the most important one that is always on the top of leadership studies is 'intelligence' (Irving, 2011). To Irving, the qualities like intelligence, integrity, enthusiasm, and any other personality trait can be enhanced or refined but cannot be invented in human beings as these traits are mostly genetic. Especially intelligence is not a fixed IQ number rather it is an epistemological machine that involves in the process of advancing itself continuously and restlessly to manage, lead and master. It is leaders distinctive force that involves in all choices especially decision making.

The Interstate School Leaders Licensure Consortium (ISLLC) developed six standards that would apply to nearly all leadership styles in education. While establishing these standards, ISLLC relied on the research on the link between educational leadership and productive schools and the trends in society and education (William et al., 2005). Thus, a school administrator is an educational leader who promotes the success of all students:

- by facilitating the development and implementation of the vision of learning.

- by advocating and nurturing a school culture conducive to student learning.

- by ensuring management of the organization as a whole for a safe and effective learning environment.

- by collaborating with community members, utilizing diverse resources and responding to community needs.

- by acting ethically, with honesty and integrity.

- by adapting, responding, and influencing political, social, legal, economic and cultural values.

To summarise, leaders may have different titles like team leader, supervisor, manager, director, president, teacher and principals. So we think a person is leader if we look to him for leadership. Leaders must continuously learn from their experiences and actively participate in their own learning and developmental goals. Leadership is defined at the Center for Creative Leadership as the "expansion of a person's capacity to be effective in leadership roles and processes". The most successful leaders continue to learn throughout their career and become aware of their strengths and limitations. They strive to improve their strengths and try to minimize the effect of their limitations (Craig and Tim, 2007). Leadership is a journey, a process, not a destination alone. It is the beginning of the next task, not the conclusion of the story. In reality leadership development is self development (James and Barry, 2008).

Leadership has nothing to do with the title, authority, or superiority. It is about using your power rightly to persuade others around you. It is about doing the best you can with the resources you already have and not making any excuse for any failure (Dave, 2012).

Leadership studies are not applicable internationally; even international studies are not applicable to every cultural group in the world (Jacky \& Gary, 2008). So this study will try to cover some parts of Asia and invites further to adapt, reject, expand, and copy it to many other parts of the world.

\section{Method of the Study}

100 Pakistani students were asked to fill out a questionnaire concerning their perceptions of the traits and behaviors of good leaders and bad leaders. The students were drawn from several schools and colleges randomly from Punjab, Province of Pakistan.

On the questionnaire, there were eight choices for each of the following:

1. Character traits of good leaders

2. Behavior traits of good leaders

3. Character traits of bad leaders

4. Behaviors traits of bad leaders

The questionnaire was given to 100 school/college students in Punjab region of Pakistan, where a common language Urdu is spoken but in all academic institutes medium of instruction is English. Thus, the sample was a homogeneous, mostly from urban schools. Since education is in English and students are highly competent and fluent in English language, so the questionnaire was given in English.

The students were asked to think of a person they considered an excellent leader, and to rank the top three leadership traits that contributed to that person to become a great leader. For the same purpose, they were also asked to rank the top three behavior characteristics that contributed to that person to become such a outstanding leader. On the other hand the students were asked to think of a person whom they knew as a bad leader and to rank the top three traits/qualities both behavioral and character that contributed to that person to become a bad leader. Here it is important to note that most of the respondents were confused to rank traits of good leaders as they could not decide whether they should mention actual traits of their previous leaders in order or the traits they prefer to see in their leaders. Then the 
question was modified accordingly as 99 percent were more comfortable in organizing the traits they wished their leaders had. Unlikely they were ready to rank negative traits of their leaders accordingly.

Analysis of the results was conducted in two phases. First choices of respondents were tabulated to see which trait of behavior and character was mentioned most often and which was neglected as a whole and which was given medium priority.

In second phase each trait or behavior was given a score depending on the rankings of the students: a first choice was given 3 point, a second choice was given 2 points, a third choice was awarded 1 point. In this way, mean score was calculated for each character and behavior trait. The various traits and behaviors could then be compared as to which one had higher mean score than others.

\section{Results}

\subsection{Traits of Good Leaders}

The percentages of respondents giving number one, two, and three rankings to the various traits, along with the mean scores for each trait, are as follows:

Table \# 1: Character trait of good leadership and highly valued

\begin{tabular}{|lcccc|}
\multicolumn{1}{c}{ Good leaders (character traits) } & $\begin{array}{c}\text { Percent- most } \\
\text { valued }\end{array}$ & $\begin{array}{c}\text { Percent- } \\
\text { valued }\end{array}$ & $\begin{array}{c}\text { Percent- } \\
\text { least valued }\end{array}$ & $\begin{array}{c}\text { MEAN } \\
\text { SCORE }\end{array}$ \\
\hline Intelligent & 28.3 & 16.4 & 15.0 & 1.33 \\
\hline good public speaker & 9.3 & 11.1 & 10.6 & 0.61 \\
\hline dependable and consistent & 4.0 & 9.7 & 8.4 & 0.4 \\
\hline broad vision shared & 7.5 & 10.2 & 9.3 & 0.52 \\
\hline friendly personality & 9.3 & 17.3 & 10.6 & 0.73 \\
\hline honest and trust worthy & 23.0 & 11.9 & 17.3 & 1.1 \\
\hline self confident & 8.4 & 12.4 & 15.5 & 0.66 \\
\hline persistence and determination in achieving goals & 10.2 & 11.1 & 13.3 & 0.66 \\
\hline
\end{tabular}

\subsection{Traits of Good Leaders}

Table \# 2: Behavioral trait of good leadership and highly valued

\begin{tabular}{|l|c|c|c|c|}
\multicolumn{1}{|c|}{ Good Leader (behavioral trait ) } & $\begin{array}{c}\text { Percent } \\
\text { Most valued }\end{array}$ & $\begin{array}{c}\text { Moderately } \\
\text { valued }\end{array}$ & $\begin{array}{c}\text { Least } \\
\text { valued }\end{array}$ & $\begin{array}{c}\text { MEAN } \\
\text { SCORE }\end{array}$ \\
\hline attended to our well being and human needs & 30.5 & 9.7 & 9.7 & 1.21 \\
\hline appealed to out higher moral values & 7.1 & 8.4 & 6.2 & 0.44 \\
\hline worked with us as a team & 19.9 & 14.2 & 12.4 & 1 \\
\hline gave clear instructions & 6.6 & 10.2 & 8.0 & 0.48 \\
\hline treated us with respect & 14.2 & 18.1 & 12.8 & 0.92 \\
\hline invited us to share in decision making & 8.4 & 13.3 & 14.6 & 0.66 \\
\hline improve social relationships & 4.9 & 11.1 & 17.7 & 0.55 \\
\hline challenged us to perform at our highest possible level & 8.4 & 15.0 & 18.6 & 0.74 \\
\hline
\end{tabular}

\subsection{Traits of Bad Leaders}

The percentages of respondents giving number one, two, and three rankings to the various traits, along with the mean scores for each trait, are as follows:

Table \# 3: Character trait of bad leadership and highly valued

\begin{tabular}{|c|c|c|c|c|}
\hline Bad leaders (Character Traits ) & $\begin{array}{c}\text { Percent } \\
\text { Most valued }\end{array}$ & $\begin{array}{l}\text { Moderately } \\
\text { valued }\end{array}$ & $\begin{array}{l}\text { Least } \\
\text { valued }\end{array}$ & $\begin{array}{l}\text { MEAN } \\
\text { SCORE }\end{array}$ \\
\hline Stupid & 21.0 & 5.8 & 3.6 & 0.78 \\
\hline could not express well & 11.2 & 7.1 & 8.5 & 0.56 \\
\hline
\end{tabular}




\begin{tabular}{|l|c|c|c|c|}
\hline say one thing and do the opposite & 24.6 & 20.5 & 11.2 & 1.26 \\
\hline narrow minded & 7.6 & 17.9 & 12.1 & 0.71 \\
\hline unfriendly personality & 3.1 & 9.8 & 8.5 & 0.37 \\
\hline dishonest and deceitful & 21.0 & 19.2 & 15.2 & 1.17 \\
\hline not confident about achieving tasks & 5.4 & 8.9 & 14.7 & 0.49 \\
\hline did not have strong will to succeed & 6.3 & 10.7 & 26.3 & 0.67 \\
\hline
\end{tabular}

\subsection{Trait of Bad Leaders}

The percentages of respondents giving number one, two, and three rankings to the various traits, along with the mean scores for each trait, are as follows:

Table \# 4: Behavioral traits of bad leadership and highly valued

\begin{tabular}{|c|c|c|c|c|}
\hline Bad leaders (behavioral traits ) & $\begin{array}{c}\text { Percent } \\
\text { Most valued }\end{array}$ & $\begin{array}{l}\text { Moderately } \\
\text { valued }\end{array}$ & $\begin{array}{l}\text { Least } \\
\text { valued }\end{array}$ & $\begin{array}{l}\text { MEAN } \\
\text { SCORES }\end{array}$ \\
\hline interested in her own ego and self promotion & 27.5 & 10.4 & 16.7 & 1.2 \\
\hline appealed to our selfishness & 9.9 & 10.4 & 7.2 & 0.58 \\
\hline no sense of team work & 14.9 & 14.0 & 9.9 & 0.83 \\
\hline did not make it clear what she wanted to do & 7.7 & 8.1 & 10.4 & 0.5 \\
\hline treated us like naughty children & 2.7 & 10.4 & 7.7 & 0.37 \\
\hline acted like a dictator & 14.4 & 12.2 & 13.1 & 0.81 \\
\hline feared criticism and opposition & 6.3 & 15.3 & 17.6 & 0.67 \\
\hline engaged in corruption and nepotism & 16.7 & 19.4 & 17.6 & 1.06 \\
\hline
\end{tabular}

\section{Discussion}

\subsection{Traits of Good Leaders (character)}

\begin{tabular}{|l|c|}
\hline \multicolumn{1}{|c|}{ Good leaders (character traits) } & MEAN SCORE \\
\hline Intelligent & 1.33 \\
\hline good public speaker & 0.61 \\
\hline dependable and consistent & 0.4 \\
\hline broad vision shared & 0.52 \\
\hline friendly personality & 0.73 \\
\hline honest and trust worthy & 1.1 \\
\hline self confident & 0.66 \\
\hline persistence and determination in achieving goals & 0.66 \\
\hline
\end{tabular}

The Pakistani students were quite clear in their assessments about good leadership traits. The most important trait that they want to see in their leaders is being intelligent having mean value as 1.3 surpassed other mean scores while the second choice was being honest and trustworthy. Having a friendly personality is taken as the thirst highest quality for a good leader. The least important trait for a good leader is being dependable and consistent.

\subsection{Traits of good leaders (behavioral)}

\begin{tabular}{|l|c|}
\multicolumn{1}{|c|}{ Good Leader (behavioral trait ) } & MEAN SCORE \\
\hline attended to our well being and human needs & 1.21 \\
\hline appealed to our higher moral values & 0.44 \\
\hline worked with us as a team & 1 \\
\hline gave clear instructions & 0.48 \\
\hline treated us with respect & 0.92 \\
\hline invited us to share in decision making & 0.66 \\
\hline improve social relationships & 0.55 \\
\hline challenged us to perform at our highest possible level & 0.74 \\
\hline
\end{tabular}


In Pakistani educational set ups, students think that leaders must take care of their subordinates and as a human being must attend to their well being. On the second stage, students usually want their leaders to treat them with respect and dignity. Or we can say that they want to see their leaders treating their employees with respect and dignity. On third level of preference they would like their leaders to challenge others to perform at the highest possible level. It is very important to note that students think appealing for higher moral values is least important trait for an educational leader.

\subsection{Traits of Bad Leaders (character)}

\begin{tabular}{|l|c|}
\hline \multicolumn{1}{|c|}{ Bad leaders (Character Traits ) } & MEAN SCORE \\
\hline Stupid & 0.78 \\
\hline could not express well & 0.56 \\
\hline say one thing and do the opposite & 1.26 \\
\hline narrow minded & 0.71 \\
\hline unfriendly personality & 0.37 \\
\hline dishonest and deceitful & 1.17 \\
\hline not confident about achieving tasks & 0.49 \\
\hline did not have strong will to succeed & 0.67 \\
\hline
\end{tabular}

In the same manner, traits of bad leaders have also been evaluated. It is evident that being an unstable person (say one thing and do the opposite) is the worst thing for a leader to be recognized as a bad one. Being dishonest and deceitful minded are rated as second highest traits of bad leaders. Stupidity is ranked as the third important trait for leaders to avoid. Being unfriendly was given least importance in the evaluation of bad leaders by college/school students.

\subsection{Traits of bad leader (behavioral)}

\begin{tabular}{|l|c|}
\multicolumn{1}{|c|}{ Bad leaders (behavioral traits ) } & MEAN SCORES \\
\hline interested in her own ego and self promotion & 1.2 \\
\hline appealed to our selfishness & 0.58 \\
\hline no sense of team work & 0.83 \\
\hline did not make it clear what she wanted to do & 0.5 \\
\hline treated us like naughty children & 0.37 \\
\hline acted like a dictator & 0.81 \\
\hline feared criticism and opposition & 0.67 \\
\hline engaged in corruption and nepotism & 1.06 \\
\hline
\end{tabular}

Pakistani students gave the highest ratings to leaders who are involved in their own ego and promotion. With a slight difference they think leaders should not be engaged in corruption and nepotism. Having no spirit of team work was rated as second highest trait for a leader to be perceived as a bad one. At the third highest level, a leader who acts like a dictator is also taken as a bad leader. Here it is important to note that not to give right instructions is a bad trait but may be excused as compared to other deadly evils.

In summary, the following are the first, second, and third ranked choices for each group:

Traits of Good Leaders (character)

- First intelligence

- Second honest and trust worthy

- Third friendly personality

Traits of Good Leaders (behavioral)

- First attended to our well being and human needs

- Second treated us with respect

- Third challenged us to perform at our highest possible level.

Character of bad Leaders

- First say one thing and do the opposite

- Second dishonest and deceifful

- Third stupid 


\section{Behavior of Bad Leaders}

- First

- Second

engaged in self promotion, corruption and nepotism

- Third

No Team Work

Thus the trait that is taken as most crucial for our society's educational leaders is intelligence which appears on the top of all good qualities and at the same time instability (no character) appears on the top of bad leadership traits. Then being honest is rated as the second highest quality in good leadership traits and also considered at second level as dishonesty in bad leadership traits. Being friendly is thought as third important trait in the evaluation of good leaders whereas stupidity is taken as third important trait to consider a leader as a bad one. If a leader is working as a team with his subordinates while treating them with respect and honor, he is thought as a good leader. On the other side, if a leader is interested in his own selfish aims and self promotional activities, he is thought as bad leader. Similarly on the other side, if he is taking care of others needs as human beings, he is thought as a good leader. If a leader is aware of the importance of team work, he/she would respect others opinions and encourage them to cooperate with each other while having some contradictory matters/views. For a leader, it is very important to know how to challenge their team members to achieve goals at their highest possible level. Whereas a leader who acts like a dictator would never like others to be successful in their set goals (or common goals) rather would force them to follow his rules blindly.

It is crystal clear that leaders are expected to be intelligent, honest and friendly with empathetic attitude and high respect for others, and at the same time encouraging team spirit and inspiring others by their selflessness. All these traits are opposite to leaders who act like dictators, interested in their own ego, dishonest, unstable, and stupid. As these two qualities could not be present at the same time in one person, it is well understood that they support each other logically and empirically.

\section{Recommendation}

According to Hofstede's researches which show a marked similarity between the two cultures, one might expect to find similarities of results between the two groups' perceptions of good and bad leaders. It is therefore recommended to judge the verification of results on other similar cultures in the country and in other south Asian countries for validity, reliability and generalizability purposes.

\section{References}

Arthur Harrison Miller.1920.leadership. NY and London:G.P.Putnam's Sons.

Craig E. Runde and Tim A. Flanagan. 2007. Becoming a Conflict Competent Leader. Jossey-Bass : CA.

Dave Weber. 2012. Leadership Redefined. The 12 x's of success for Todays Leader. Weber: USA.

David J.Worthington. (2012). How To Develop Leadership. Enirtak Inc: Ebook

Frank Damazio.1988. The making of a leader. City Christian Publishing: U.S.A.

Irving H. Buchen. 2011. Executive Intelligence: The Leaders Edge. Rowman \& Littlefield Publishers, Inc: UK.

Irving H. Buchen. 2011. The Hybrid Leader: Evolving, Adaptable, Unfinished. Rowman \& Littlefield Publishers, Inc : UK.

Jacky Lumby \& Gary Crow (Ed).2008. International handbook on the preparation and development of school leaders. Routledge: UK.

James M. Kouzes and Barry Z.Posner. 2008. The Student Leadership Challenge. Jossey - Bass : CA.

Jeffrey Cohn and Jay Moran. 2011. Why are we bad at picking good leaders? CA: Jossey-Bass.

Kenneth Leithwood, Alma Harris, and Tiiu Strauss. 2010. Leading School Turnaround. Jossey-Boss: CA.

Larry F. Ross, Sr. (2008). So you want to be a strategic leader. MN;USA: Xlibris Corporation.

Richard Selwyn. 2012. outcomes \& efficiency: Leadership Handbook. PIPC UK Ltd: Uk.

Robert Palestini.2009. From Leadership Theory To Practice. USA: Rawman and Littlefield Education.

Sharon D. Kruse. 2009. Working Smart: Problem-Solving Strategies for School Leaders. Rowman \& Littlefield Education: UK.

Stephan Gerhard Huber. 2004. Preparing School Leaders For the 21st Century. Taylor \& Francis Group plc : UK.

William L. Sharp, James K. Walter, \& Helen M. Sharp. 2005. Case Studies for School Leaders. Rowman \& Littlefield Publishers, Inc: UK. 